\title{
Groundwater storage effects from restoring, constructing or draining wetlands in temperate and boreal climates: a systematic review protocol
}

\author{
Arvid Bring $^{1 *} \mathbb{D}$, Lars Rosén ${ }^{2}$, Josefin Thorslund ${ }^{3}$, Karin Tonderski ${ }^{4}$, Charlotte Åberg ${ }^{1}$, Ida Envall ${ }^{1}$
} and Hjalmar Laudon ${ }^{5}$

\begin{abstract}
Background: Wetlands in many parts of the world have been degraded, as use of the land for food production and forestry for human needs have taken precedence. Drainage of wetlands has led to deteriorated wetland conditions and lowered water tables. Across the world, there are several programs for wetland restoration and construction, primarily to reintroduce lost habitats for wild life, and to obtain nutrient retention functions. In Sweden, recent dry and hot summers have reinforced interest in the hydrological functions that wetlands may have, in particular as potential support for water storage in the landscape and added groundwater storage during dry periods. However, the agreement on substantial effects on groundwater is limited, and there are several critical knowledge gaps, including the extent to which such effects extend outside the wetland itself, and how they vary with local conditions, such as topography, soil, and climate. Therefore, this review will address the groundwater storage effect of restoring, constructing or draining wetlands in the boreo-temperate region.

Methods: We will conduct a systematic review of the evidence, drawing on both peer-reviewed and grey literature. Articles in English, Swedish, Norwegian, Danish, French, German and Polish will be retrieved from academic databases, Google Scholar, and websites of specialist organizations. We will screen literature in two stages, first at the title and abstract level and then in full text, the latter with blinded decisions by two independent reviewers for all articles. Articles will be included based on relevance criteria for a Swedish context: wetlands on previously glaciated soils in boreal and temperate climates. Data will be extracted from all included articles, including wetland type, intervention type, and hydrogeological setting. Studies will be subject to critical appraisal to evaluate their susceptibility to bias. Provided enough evidence of sufficient reliability, we will carry out meta-analyses of effect sizes in relation to various factors. The review will include a narrative synthesis in which we summarize the results of the review.
\end{abstract}

Keywords: Peatland, Bog, Fen, Mire, Water table, Hydrology, Hydrogeology, Evidence synthesis, Environmental management

*Correspondence: arvid.bring@formas.se

${ }^{1}$ The Swedish Research Council for Environment, Agricultural Sciences and Spatial Planning (Formas), P.O. Box 1206, 11182 Stockholm, Sweden

Full list of author information is available at the end of the article

\section{Background}

Wetlands are among the most degraded ecosystems globally [1]. Many degraded wetlands are in urgent need of restoration in order to regain their natural characteristics and re-establish their physical, chemical, and biological functions. Approximately $87 \%$ of the

c) The Author(s) 2020. This article is licensed under a Creative Commons Attribution 4.0 International License, which permits use, sharing, adaptation, distribution and reproduction in any medium or format, as long as you give appropriate credit to the original author(s) and the source, provide a link to the Creative Commons licence, and indicate if changes were made. The images or other third party material in this article are included in the article's Creative Commons licence, unless indicated otherwise in a credit line to the material. If material is not included in the article's Creative Commons licence and your intended use is not permitted by statutory regulation or exceeds the permitted use, you will need to obtain permission directly from the copyright holder. To view a copy of this licence, visit http://creativeco mmons.org/licenses/by/4.0/. The Creative Commons Public Domain Dedication waiver (http://creativecommons.org/publicdomain/ zero/1.0/) applies to the data made available in this article, unless otherwise stated in a credit line to the data. 
global wetlands have been degraded the last 300 years, $50 \%$ since the beginning of the twentieth century [2]. Wetland degradation are common in both coastal and inland areas, although the inland systems have been especially affected [3].

Wetlands are ecosystems that, either permanently or seasonally, are flooded resulting in oxygen-free reducing environmental conditions. Natural wetlands have several important ecosystem functions, including water purification [4], water storage [5], carbon sequestration [6], shoreline stabilization [7] and unique habitats [8]. As such, natural wetlands are some of the most biodiverse ecosystems globally, serving as habitats for a large range of plant and animal species [9].

At northern latitudes, many wetlands are peat-forming mires (bogs, fens and mixed mires) with important carbon sequestration functions. Other northern wetlands consist of coastal and limnic shore wetlands, as well as other wetland types that are formed directly on mineral soils. An important hydrological distinction between wetland types is the predominant source of water supporting the wetland ecosystem, i.e., precipitation, groundwater, or surface water.

Historically, substantial wetland areas were formed on temporary flooded floodplains and lake shores. With increased water level regulation to harness energy or create agricultural land, the area of such riparian wetlands has dramatically decreased [1]. Many other types of wetlands have also been drained for agricultural or forestry purposes, and thereafter ceased to be wetlands as human induced ditch-networks efficiently removed the water and prevented the natural flooding regime. In Sweden alone, over 1 million $\mathrm{km}$ of ditches were dug-mostly by hand on peatlands-the last century to improve forest and agricultural productivity [10]. This is equal to the length of all natural streams and rivers in the country. Drainage has lowered the water table, which has resulted in increased bulk density of the peat, which in turn has led to decreased hydraulic conductivity $[11,12]$. This so-called peat subsidence is the most important factor causing ditches to become shallower with time [13], but also suggests that wetland drainage can cause irreversible changes to their hydrological function.

Wetlands typically develop in groundwater discharge areas. Restoration of wetlands can therefore impact groundwater systems hydraulically, resulting in effects on groundwater quantity as well as quality, e.g. changes in groundwater levels, storage, chemical and microbial composition. The wetland restoration efforts may thus affect groundwater dependent ecosystems as well as ecosystem services such as the potential of geological formations to serve as aquifers for drinking water or irrigation.
In Sweden, recent extreme heatwaves, culminating with the 2018 drought, has increased the interest in how restorations of wetlands, though primarily targeting other functions such as physical, chemical, and biological aspects, affect groundwater storage and recharge. Restored wetlands clearly affect local hydrology by recreating wetland conditions, which in turn often involve a raising of the local water table. However, the magnitude and spatial extent of this effect for various types of wetlands, interventions, and site conditions, as well as the potential effect on groundwater recharge to the underlying or adjacent aquifer, have not been univocally demonstrated.

Several knowledge gaps remain with regards to wetland hydrological functions and their changes under hydroclimatic and human influences. For example, changes in land use (including both creation, restoration and drainage of wetlands), water use, climate and demographic pressures all affect landscape water fluxes and balances (e.g., $[14,15])$. However, the net effects of such changes on wetland hydrological functions (including groundwater regulation and recharge) across wetland types, regions and scales remain largely unknown [16]. Although wetland drainage and its hydrological impacts have been studied extensively, results are often based on local, individual wetland conditions, with the lack of assessments beyond and between individual wetland borders [17]. Improving this knowledge of wetland hydrological functions under current and future changes requires sciencebased management and regulatory responses at multiple levels [18].

Swedish support for wetland restoration and creation has recently been reinforced for projects with water retention and water storage purposes. New or expanded wetland drainage also occurs in Sweden, mostly in connection with infrastructure projects, renewed permits for peat extraction, or for maintenance of the extensive drainage networks that already exist. The Swedish Geological Survey (SGU) is responsible for Sweden's national environmental objective to have a groundwater of good quality. SGU also assists other government agencies in reviewing both restoration and drainage projects from a hydrogeological perspective.

In line with the knowledge gaps outlined above, SGU has also noted a limited knowledge of groundwater effects from wetland restoration, creation and drainage in a Swedish context [19]. Therefore, SGU has suggested that Formas, the Swedish Research Council for Environment, Agricultural Sciences and Spatial Planning, should investigate this topic. After a pilot study by Formas, the Council for Evidence-Based Environmental Analysis has decided that Formas should conduct a systematic review of the evidence. 
To evaluate the effect of wetland interventions on groundwater storage, we will perform a systematic review including both peer-reviewed and grey literature (e.g., non-peer reviewed reports and student theses). We will provide a meta-analysis of the magnitude of change in groundwater storage following wetland creation, restoration and drainage, to the extent that existing literature allows an assessment to be made. The analysis will also provide an indication of uncertainty ranges and potential gaps and shortcomings in the available literature.

\section{Stakeholder engagement}

During the writing of the protocol, consultations have been held with several stakeholders, primarily government agencies with a mandate that involves hydrological effects from wetland creation, restoration and drainage. These include the Swedish Environmental Protection Agency, the Swedish Meteorological and Hydrological Institute, the Swedish Food Agency, and regional County Administrative Boards who oversee wetland restoration projects. Additional consultation has been held with municipalities and non-government associations, including forest and farm owners, as well as nature conservation societies. Several researchers have been contacted with specific questions. Stakeholders have been invited to comment on the protocol before submission and will be invited to review the results of the review before publication.

The results of the review are expected to be useful for SGU and the Swedish Environmental Protection Agency in assessing the possible effects of wetland restoration, creation and drainage in various hydrogeological settings relevant for a Swedish context. The results are also expected to be of use to county administrative boards who are involved in wetland project applications, and to municipalities, land owners, and environmental associations who are considering where a wetland project may have the greatest effect on the groundwater storage.

\section{Objective of the review}

The primary question of this systematic review is:

What is the effect on groundwater storage from restoring, constructing or draining wetlands in temperate and boreal climates?

Of particular interest are effects in areas that are adjacent to the wetland, as opposed to within the treated wetland. We expect, however, that studies that report such effects will be few, and therefore will also include studies that have reported effects within the affected wetland only.

A secondary question is the possible role of factors that could influence the effect.
The main question can be separated into the following elements:

Population: Groundwater in temperate and boreal climates in previously glaciated areas.

Intervention: Restoration, construction or drainage of wetlands.

Comparator: No intervention.

Outcome: Change in groundwater level, storage or amount.

The elements of the question are further defined in the section on article screening and study inclusion criteria below.

\section{Methods}

This review will follow the Collaboration for Environmental Evidence guidelines [20] and conform to the ROSES reporting standards [21]. The ROSES form is available in Additional file 1.

\section{Searching for articles}

Searches will be made for peer-reviewed articles and grey literature using bibliographic databases, search engines, websites of relevant organizations and stakeholder contacts. The reference management software EndNote will be used to collect all search results and to remove duplicates.

\section{Bibliographic database search}

Searches will be made in the eight bibliographic databases and platforms listed in Table 1. The search string will be adapted to the specific syntax in each database. All the adapted search strings and matching results will be published in the final review.

We will use a search string that consists of two search blocks, one search block with intervention terms (restoration, construction or drainage of wetlands) and one search block with outcome terms (change in groundwater level, storage or amount). The search string, adapted to the bibliographic database Scopus, can be found in Additional file 2. The searches will not be limited by date or document type, but the searches will be limited to language, finding documents in English, Danish, French, German, Norwegian, Polish, and Swedish.

The search terms were derived from a combination of different approaches:

- Brainstorming within the review team.

- Many of the wetland terms were retrieved from previous systematic reviews [22-24].

- More search terms (both English and Swedish) were found in the dictionary from the Swedish Hydrological Council [25]. 
Table 1 Bibliographic databases to be searched

\begin{tabular}{|c|c|c|c|}
\hline Database/platform & Search field & Language of search terms & Subscription information \\
\hline Scopus & Title, Abstract, Keywords & English & $\begin{array}{l}\text { Swedish Research Council Formas } \\
\text { subscription }\end{array}$ \\
\hline Web of Science Core Collection & $\begin{array}{l}\text { Topic (search the fields: title, abstract } \\
\text { and keywords) }\end{array}$ & English & $\begin{array}{l}\text { Swedish Research Council Formas } \\
\text { subscription includes: } \\
\text { Science Citation Index Expanded; } \\
\text { Social Sciences Citation Index; Arts \& } \\
\text { Humanities Citation Index; Confer- } \\
\text { ence Proceedings Citation Index- } \\
\text { Science; Conference Proceedings } \\
\text { Citation Index- Social Science \& } \\
\text { Humanities; Emerging Sources Cita- } \\
\text { tion Index }\end{array}$ \\
\hline Academic Search Premier & $\begin{array}{l}\text { Title, Abstract, Subject Terms, Author- } \\
\text { Supplied Keywords }\end{array}$ & English & $\begin{array}{l}\text { Swedish Research Council Formas } \\
\text { subscription on Ebsco platform }\end{array}$ \\
\hline CAB Abstracts & Title, Abstract, Heading Words & English & $\begin{array}{l}\text { Swedish Research Council Formas } \\
\text { subscription on Ovid platform }\end{array}$ \\
\hline Directory of Open Access Journals ${ }^{a}$ & All fields & English & Free, does not require a subscription \\
\hline DiVA $^{a}$ & All fields & English and Swedish & Free, does not require a subscription \\
\hline ProQuest Natural Science Collection & Title, Abstract, All subjects \& indexing & English & $\begin{array}{l}\text { Swedish Research Council Formas } \\
\text { subscription includes: } \\
\text { AGRICOLA; Agricultural Science } \\
\text { database; Aquatic Sciences and } \\
\text { Fisheries Abstracts; Biological Science } \\
\text { database; Biological Science index; } \\
\text { Earth, atmosphere \& Aquatic Science } \\
\text { database; Environmental Science } \\
\text { database; Environmental Science } \\
\text { index; Meteorological \& Geoastro- } \\
\text { physical Abstracts }\end{array}$ \\
\hline SwePuba & All fields & English and Swedish & Free, does not require a subscription \\
\hline
\end{tabular}

a A simplified search string will be used and published in the final report

- The list of search terms identified where evaluated by the subject experts in the review team. Irrelevant terms were deleted and new terms were added after consulting with the experts.

- A list of benchmark studies (see Additional file 3) were used during the development of the search string and to test the comprehensiveness of the search. The bibliographic database Scopus was used when developing the search string and testing whether the benchmark studies were found. If any of the benchmark studies had been missed, the search string was adapted to include the missed studies. The search string in Additional file 2 retrieves all the benchmark studies.

\section{Search engines}

We will search Google Scholar, using simple search strings in English and Swedish. The search strings for Google Scholar can be found in Additional file 2. The first 200 results from each search string will be exported from Google Scholar using Publish or Perish software [26].

\section{Websites of relevant organizations}

In order to find grey literature, we will search the websites of relevant organizations, listed in Table 2. Simple search strings will be used, adapted to the search capabilities of each website. Both English and Swedish search terms will be used, depending on the appropriate language for each website. All search strings and matching results will be published in the final review.

\section{Supplementary searches}

We will contact stakeholders and experts in the field to request studies and reports. If we identify relevant reviews during the article screening process, we will look through the bibliographies of these reviews and include relevant literature not already identified.

\section{Article screening and study eligibility criteria}

Articles will be screened in two stages. First, all results will be screened on title and abstract. At this stage, articles will be classified into three categories: (1) include, (2) exclude, and (3) probably exclude. Double screening by two independent screeners will be performed 
Table 2 Websites to be searched

\begin{tabular}{|c|c|c|}
\hline Organization & URL & Language of search terms \\
\hline \multicolumn{3}{|l|}{ Organizations in Europe } \\
\hline EEA (European Environment Agency) & https://www.eea.europa.eu & English \\
\hline European Commission Joint Research Centre & $\begin{array}{l}\text { https://ec.europa.eu/info/departments/joint-research-centr } \\
\text { e_en }\end{array}$ & English \\
\hline Miljøstyrelsen (Danish Environmental Protection Agency) & https://mst.dk & English \\
\hline Luke (Natural Resources Institute Finland) & https://www.luke.fi & English and Swedish \\
\hline $\begin{array}{l}\text { Metsähallitus (Steward of state-owned land and water } \\
\text { areas in Finland) }\end{array}$ & $\begin{array}{l}\text { https://www.metsa.fi/ } \\
\text { https://julkaisut.metsa.fi/ }\end{array}$ & English and Swedish \\
\hline SYKE (Finnish Environment Institute) & https://www.syke.fi & English and Swedish \\
\hline Environment Protection Agency Ireland & https://epa.ie/ & English \\
\hline Deltares & https://www.deltares.nl/en/ & English \\
\hline PBL Netherlands Environmental Assessment Agency & https://www.pbl.nl/ & English \\
\hline NIVA (Norwegian Institute for Water Research) & https://www.niva.no/ & English \\
\hline IVL (Swedish Environmental Research Institute) & https://www.ivl.se & English and Swedish \\
\hline Jordbruksverket (Swedish Board of Agriculture) & https://jordbruksverket.se/ & Swedish \\
\hline $\begin{array}{l}\text { Länsstyrelser i Sverige (County Administrative Boards in } \\
\text { Sweden) }\end{array}$ & https://www.lansstyrelsen.se & Swedish \\
\hline $\begin{array}{l}\text { Naturvårdsverket (Swedish Environmental Protection } \\
\text { Agency) }\end{array}$ & https://www.naturvardsverket.se & Swedish \\
\hline SGU (Geological Survey of Sweden) & https://www.sgu.se & Swedish \\
\hline Skogsstyrelsen (Swedish Forest Agency) & https://www.skogsstyrelsen.se/ & Swedish \\
\hline SMED (Swedish Environmental Emissions Data) & https://www.smed.se/ & Swedish \\
\hline SMHI (Swedish Meteorological and Hydrological Institute) & https://www.smhi.se/ & English and Swedish \\
\hline SKB (Swedish Nuclear Waste Management Company) & https://www.skb.se/ & Swedish \\
\hline Vattenmyndigheterna (Swedish Water Authorities) & https://www.vattenmyndigheterna.se/ & Swedish \\
\hline DEFRA (Department for Environment, Food \& Rural Affairs) & $\begin{array}{l}\text { https://www.gov.uk/government/organisations/depar } \\
\text { tment-for-environment-food-rural-affairs }\end{array}$ & English \\
\hline Scottish Environmental Protection Agency & https://www.sepa.org.uk & English \\
\hline UK Centre for Ecology \& Hydrology & https://www.ceh.ac.uk/ & English \\
\hline UK Environment Agency & $\begin{array}{l}\text { https://www.gov.uk/government/organisations/envir } \\
\text { onment-agency }\end{array}$ & English \\
\hline \multicolumn{3}{|l|}{ Organizations in North America } \\
\hline Association of State Wetland Managers & https://www.aswm.org/ & English \\
\hline Environment and Climate Change Canada & $\begin{array}{l}\text { https://www.canada.ca/en/environment-climate-chang } \\
\text { e.html }\end{array}$ & English \\
\hline U.S. Environmental Protection Agency & https://www.epa.gov/ & English \\
\hline U.S. Geological Survey & https://www.usgs.gov/ & English \\
\hline \multicolumn{3}{|l|}{ International organizations } \\
\hline GWEN (Global Wetland Ecohydrology Network) & https://www.gwennetwork.se/ & English \\
\hline Ramsar & https://ramsar.org/ & English \\
\hline Society of Wetland Scientists & https://www.sws.org/ & English \\
\hline Wetlands International & https://www.wetlands.org/ & English \\
\hline
\end{tabular}

for a subset of the articles $(n \geq 300)$, iteratively until sufficient agreement (c. $80 \%$ ) is met and to ensure that the criteria are being consistently applied. Articles in category (3) will then be separately screened by another author, in order to minimize the risk of erroneously excluding any articles. Due to the expected large volume of abstracts, articles excluded at the title and abstract stage will not be coded with a reason for exclusion.

In the second stage, all articles that have passed from the first stage will be screened in full text independently by two authors, and any disagreements will be reconciled through discussion with all authors. 
Authors of the review will not be allowed to assess the inclusion or exclusion of their own studies at the screening stage. A list of articles excluded at full text, together with reasons for exclusion, will be provided.

\section{Eligible populations}

The study focuses on groundwater and ground conditions relevant for Sweden. The area of study must therefore be in Köppen-Geiger climate classification zones BSk, C, or $\mathrm{D}$ (cold semi-arid climates, temperate climates, or continental climates; Fig. 1). Studies must also have been performed in areas that have been subject to glaciation during the Quaternary geological period (last 2.5 million years). Studies in areas subject to the most recent glaciation, i.e., the last glacial maximum, are considered the most relevant and of the highest priority. Glaciated areas exhibit fundamentally different hydrogeological conditions than non-glaciated areas due to the geological formations formed during glaciations [27]. Thus, the motivation for these criteria is that wetland vegetation types, water balance conditions including evapotranspiration, and groundwater movement and storage are strongly influenced by the geological and climatic setting. Therefore, studies performed outside of the geographical scope of this review are expected to have less external validity for conditions in Sweden and other areas that have been subject to recent glaciation. We will determine eligibility according to the glaciation history on a case by case basis, aided by maps of Quaternary glaciation extent that are available also in digital format [28]. In cases of doubt, we will evaluate the site description in the study to determine eligibility.

\section{Eligible interventions}

Since the effects of restoration and construction are quite different from the effects of drainage, we have separated the definitions of eligible interventions for the two types of interventions. The motivation for including not only restored and constructed, but also drained wetlands, is threefold. First, knowledge of the original drainage effect is of relevance for evaluating how far restoration could possibly go in reinforcing groundwater storage towards undrained wetland conditions. Second, although restoration and construction are the key effects of interest, several stakeholders also have interest in drainage effects in relation to permit applications for a limited number of new drainage projects or maintenance of present drainage. Third, in cases where it is not possible or desirable to fully restore drained soils to wetlands, limiting or controlling the magnitude of drainage may be a potential option to still achieve some benefits of reinforced groundwater storage.

Restoration or construction of wetlands Included: Restoration or construction actions that aim to partially or fully restore or create wetland conditions, for example: ditch blocking, check dams, dam restoration, damming, restored shoreline wetlands (wetlands created as result of lake level change or restoration), vegetation removal, remeandering of streams, riparian overflow zones, ditch overflow zones, farm ponds, nutrient retention ponds, wetland creation on soil that was not a wetland prior to the intervention.

Not included: Water reservoirs that are not wetlands (e.g., deep reservoirs for hydropower or irrigation), subsurface flow treatment wetlands, constructed treatment

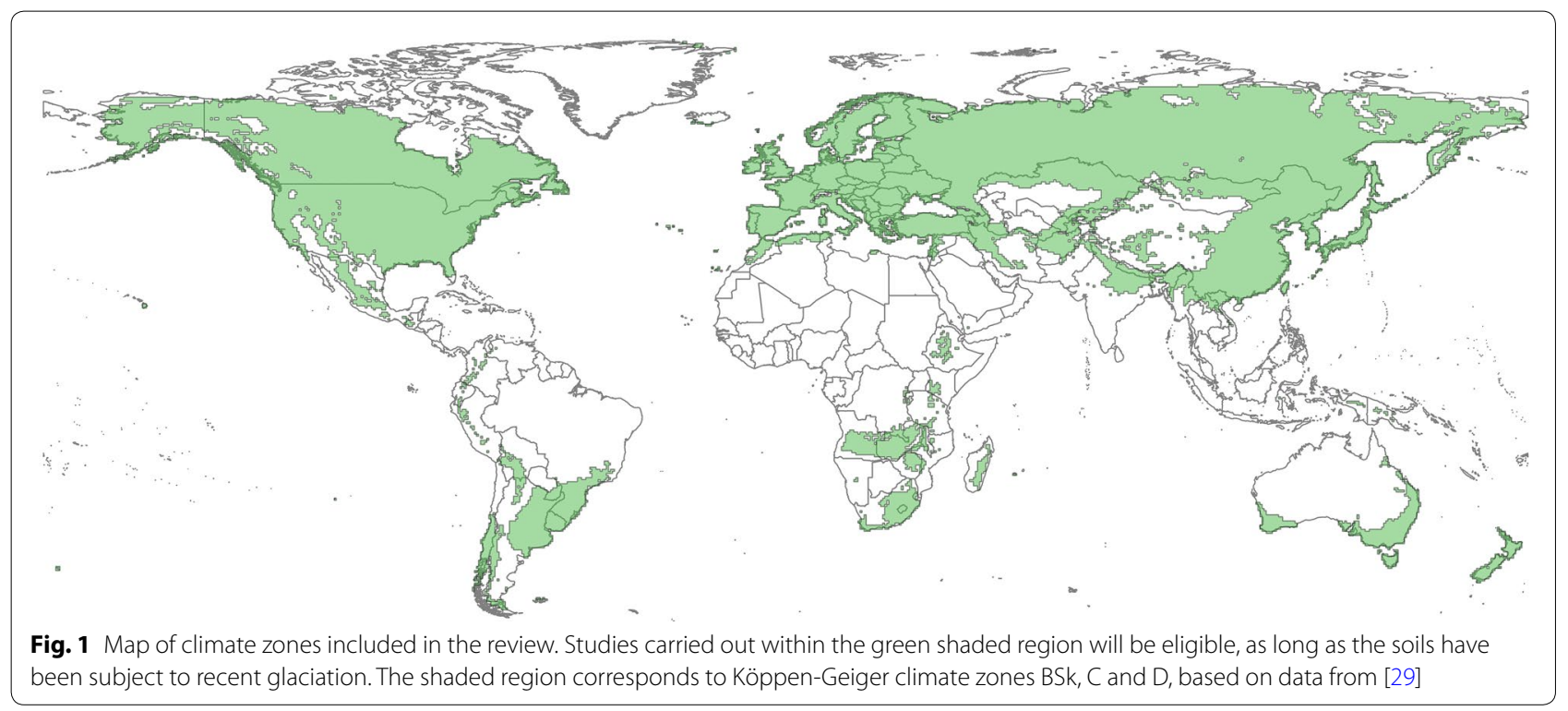


wetlands that are not connected to the surrounding soils/ groundwater, artificial raising of the water table with specific amounts as a control variable (unless independent groundwater outcomes are reported for other parts of the wetland, or in adjacent soils).

Drainage of wetlands Included: Drainage actions that aim to partially or fully drain wetland areas, for example ditching, ditch maintenance or re-excavation to original depth, ditch deepening, dam removal, other water table lowering measures.

Not included: Drained soils that are not or have not been wetlands, subsurface drainage, drainage through pipes or pumping, drainage of constructed wetlands that are not connected to the surrounding soils/groundwater, artificial lowering of the water table with specific amounts as a control variable (unless independent groundwater outcomes are reported for other parts of the wetland, or in adjacent soils).

General We will exclude the following wetland types: Coastal wetlands strongly influenced by tides, salt water or brackish waters.

We will use a classification scheme that we have initially developed to categorize interventions of relevance in a Swedish context. This classification scheme will be adapted during screening to form a useful scheme for interventions relevant in Sweden.

\section{Eligible comparators}

The study must include a control. The control area should ideally be the same area before the intervention (Before-After studies). However, studies that use a similar area not subject to the intervention as control (Control-Impact studies) are also accepted. Such studies must be designed so that the effect of the intervention can be evaluated.

\section{Eligible outcomes}

Measures that allow direct assessment of groundwater level, storage or amount. The outcome should be reported within the wetland, or in its near vicinity, both for the intervention site or time and a corresponding control site or period (or both).

Groundwater measurements outside the wetland (apart from control sites) are of particular interest and will be recorded, but such measurements are not required for inclusion. Hydraulic head, pump tests, or other measurements that can be directly interpreted as groundwater levels or amount are also accepted. Surface water level measurements of different kinds (in situ and aerial/satellite), such as the depth of water in the wetland, are not included.

\section{Eligible study types and publication languages}

All types of controlled and observational studies are included. We will however exclude the following study types: Laboratory studies, greenhouse studies, and model studies that do not report empirical validation data fulfilling our eligibility criteria.

We will include publications written in English, Danish, French, German, Norwegian, Polish, and Swedish.

\section{Study validity assessment}

We will not appraise external validity, as this is likely dependent on the context of interest to the reader. For example, studies of peat wetlands may be highly relevant to certain readers, whereas others will only be interested in results of relevance in sandy soils. However, the criteria for study inclusion are formulated to ensure external validity for Swedish conditions.

The basis for assessing internal validity will center on the criteria in Table 3. The criteria are intended to aid assessment of risk of bias, mainly in terms of selection bias and performance bias. The purpose of the critical assessment is to reduce the risk that the conclusions of the review are misleading.

Authors of the review will not be allowed to perform critical appraisal of their own work. All critical appraisal decisions will be reviewed by another author to ensure consistency, and any disagreements will be discussed with the entire review team. Studies that are judged to be of very low validity for answering the question may be excluded from the review. Provided a sufficient number of studies, analysis of results will be performed with and without studies with high susceptibility to bias. All studies that are excluded after critical appraisal will be listed in the review, together with a reason for exclusion.

\section{Data coding and extraction strategy}

We will extract data on study design, wetland type and geographical context, intervention, and study results. Outcome data will include sample size, mean, and variability (standard deviation, standard error, or confidence intervals). Data will be extracted to a spreadsheet with predetermined coding where applicable. If there are several independent investigations in the same article, these will be treated as separate studies in the database table.

A draft version of the data extraction questionnaire is presented in Table 4. During the review process, the table may be revised or modified to accommodate additional information. Before commencement of full data extraction, the questionnaire will be tested on a subset (approximately $10 \%$ ) of studies by two reviewers independently. Any uncertainty in data extraction will be discussed with 


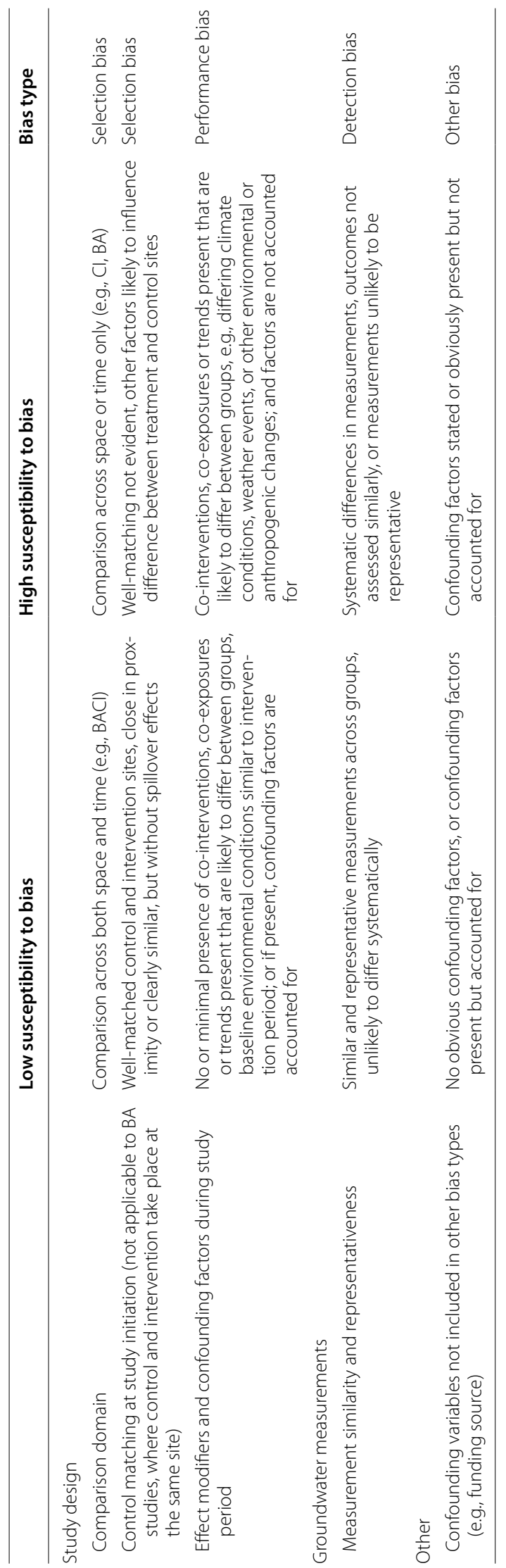


Table 4 Draft version of metadata extraction questionnaire

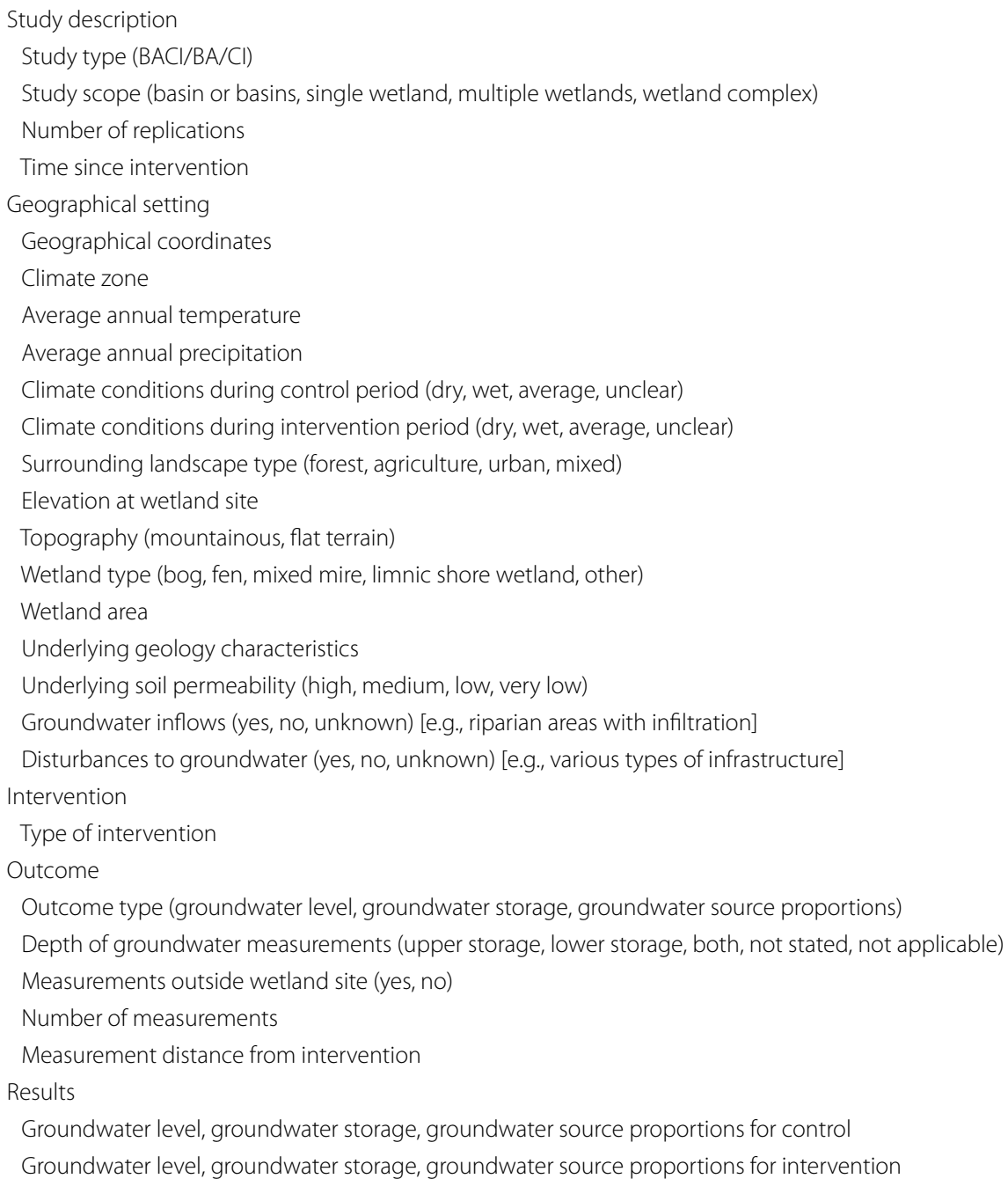

Items that are listed with alternatives in parentheses will be coded. Other items will be entered as descriptive or numerical information

an additional reviewer, and remaining questions will be resolved through discussion with the entire review team, until agreement is reached.

If data are unavailable or incomplete, we will contact authors to attempt to obtain the missing information. All data extracted from the studies will be provided with the review as a separate appendix.

\section{Potential effect modifiers/reasons for heterogeneity}

We expect that several factors may influence effects on groundwater storage, and list the ones thought to be most important here. For these variables, we will analyze their influence on the results, if we find sufficient data in the identified studies.

- Permeability of soils
- Type of intervention

- Distance from intervention

- Climate conditions

- Type of wetland

- Measurements in wetland or in adjacent areas

We also expect that the criteria for critical appraisal may be reason for variation in outcome, and will consider them as potential effect modifiers. Additional effect modifiers or reasons for heterogeneity may be added during the review process.

\section{Data synthesis and presentation}

We will conduct a narrative synthesis with tables, figures and descriptive statistics that support interpretation of results. In the summary results, we will show statistics 
for the main geographical characteristics of study sites, for example wetland type and climate. A map of locations of the included studies will be provided. We also aim to perform a quantitative meta-analysis of studies, if sufficient data from studies with appropriate validity are available. Studies with low validity may be excluded from the analysis. Provided enough data, we will consider the potential effect modifiers and critical appraisal criteria as covariates in a meta-regression analysis. We will also perform a sensitivity analysis where studies with different risks of bias are included or excluded, to investigate any effect study methodology may have on the reported outcomes. The risk of publication bias will be investigated through funnel plots. These investigations will support interpretations of the review findings, and may inform future decisions on research methods that are appropriate for investigating the review question. Knowledge gaps will be identified by visual inspection of heat maps created by cross-tabulating different key descriptors. These knowledge gaps, and any challenges with drawing on the evidence base, will be discussed with respect to the possibility to answer the review question.

\section{Supplementary information}

Supplementary information accompanies this paper at https://doi. org/10.1186/s13750-020-00209-5.

Additional file 1. Our adherence to the ROSES standards for systematic review protocols.

Additional file 2. Search strings adapted to Scopus and Google Scholar.

Additional file 3. List of benchmark studies used to test the comprehensiveness of the search.

\section{Acknowledgements}

The forthcoming review has been commissioned by the Council for EvidenceBased Environmental Analysis at Formas, after an initial question formulated by the Swedish Geological Survey (SGU). We thank a number of stakeholders and reviewers for comments that have improved the manuscript.

\section{Authors' contributions}

$H L, J T, L R$ and $K T$ wrote the first draft of the manuscript introduction. $C \AA$ developed the search strategy in collaboration with other authors. AB drafted the remaining sections. All authors contributed to the plan for study design, manuscript editing and revisions. All authors read and approved the final manuscript.

\section{Funding}

Open Access funding provided by Swedish Research Council Formas. This protocol and the forthcoming review are financed by Formas, a Swedish research council for sustainable development, to which three of the authors (AB, IE and CA) are affiliated. HL, JT, LR and KT were funded by Formas.

\section{Availability of data and materials}

Data sharing is not applicable to this article as no datasets were generated or analyzed during the current study.

Ethics approval and consent to participate Not applicable.
Consent for publication

Not applicable.

\section{Competing interests}

The authors and the funding body Formas declare that they have no competing interests.

\section{Author details}

${ }^{1}$ The Swedish Research Council for Environment, Agricultural Sciences and Spatial Planning (Formas), P.O. Box 1206, 11182 Stockholm, Sweden. 2 Department of Architecture and Civil Engineering, Chalmers University of Technology, SE-412 96, Gothenburg, Sweden. ${ }^{3}$ Department of Physical Geography, Stockholm University, 10691 Stockholm, Sweden. ${ }^{4}$ Department of Management and Engineering (IEI), Linköping University, 58183 Linköping, Sweden. ${ }^{5}$ Department of Forest Ecology and Management, Swedish University of Agricultural Sciences, 90183 Umeå, Sweden.

Received: 14 July 2020 Accepted: 10 October 2020

Published online: 21 October 2020

\section{References}

1. Ramsar Convention on Wetlands. Global wetland outlook: state of the world's wetlands and their services to people. Gland: Ramsar Convention Secretariat; 2018.

2. Davidson NC. How much wetland has the world lost? Long-term and recent trends in global wetland area. Mar Freshw Res. 2018. https://doi. org/10.1071/MF14173.

3. Evans JP, Cecala KK, Scheffers BR, Oldfield CA, Hollingshead NA, Haskell DG, McKenzie BA. Widespread degradation of a vernal pool network in the southeastern United States: challenges to current and future management. Wetlands. 2017;37:1093-103.

4. Chalov S, Thorslund J, Kasimov N, Aybullatov D, llyicheva E, Karthe D, Kositsky A, Lychagin M, Nittrouer J, Pavlov M, Pietron J, Shinkareva G, Tarasov M, Garmaev E, Akhtman Y, Jarsjö J. The Selenga River delta: a geochemical barrier protecting Lake Baikal waters. Reg Environ Chang. 2017;17:2039-53.

5. Ameli AA, Creed IF. Groundwaters at risk: wetland loss changes sources, lengthens pathways, and decelerates rejuvenation of groundwater resources. J Am Water ResourAssoc. 2019;55:294-306. https://doi. org/10.1111/1752-1688.12690.

6. Mitsch WJ, Bernal B, Nahlik AM, Mander Ü, Zhang L, Anderson CJ, Jørgensen SE, Brix H. Wetlands, carbon, and climate change. Landscape Ecol. 2013;28:583-97. https://doi.org/10.1007/s10980-012-9758-8.

7. Gedan KB, Kirwan ML, Wolanski E, Barbier EB, Silliman BR. The present and future role of coastal wetland vegetation in protecting shorelines: answering recent challenges to the paradigm. Climatic Change. 2011;106:7-29. https://doi.org/10.1007/s10584-010-0003-7.

8. Sharitz RR. Carolina bay wetlands: unique habitats of the southeastern United States. Wetlands. 2003;23:550-62. https://doi.org/10.1672/02775212(2003)023[0550:CBWUHO]2.0.CO;2.

9. Gibbs JP. Wetland loss and biodiversity conservation. Conserv Biol. 2001;14:314-7.

10. Hånell B. Möjlighet till höjning av skogsproduktionen i Sverige genom dikesrensning, dikning och gödsling av torvmarker (Possibility of increasing forestry production in Sweden through ditch maintenance, ditching and fertilizing on peatlands; in Swedish). In: Fahlvik N, Johansson U, Nilsson U, editors. Skogsskötsel för ökad tillväxt (Forest management for increased growth; in Swedish). SLU, Rapport. ISBN 978-91-86197-43-8. Appendix 4:1-28.

11. Silins $U$, Rothwell RL. Forest peatland drainage and subsidence affect soil water retention and transport properties in an Alberta peatland. Soil Sci Soc Am J. 1998;62:1048-56.

12. Price JS, Heathwaite AL, Baird AJ. Hydrological processes in abandoned and restored peatlands: an overview of management approaches. Wetland Ecol Manage. 2003;11:65-83.

13. Heikurainen $L$. Changes in depth and top width of forest ditches and the maintaining of their repair. Acta ForestaliaFennica. 1957;65:1-45. 
14. Kaushal SS, Gold AJ, Mayer PM. Land use, climate, and water resourcesglobal stages of interaction. Water. 2017;9:1-10. https://doi.org/10.3390/ w9100815.

15. Ghajarnia N, Destouni G, Thorslund J, Kalantari Z, Åhlén I, Anaya-Acevedo JA, Blanco-Libreros JF, Borja S, Chalov S, Chalova A, Chun KP, Clerici N, Desormeaux A, Garfield BB, Girard P, Gorelits O, Hansen A, Jaramillo F, Jarsjö J, Labbaci A, Livsey J, Maneas G, McCurleyPisarello K, PalominoÁngel S, Pietroń J, Price RM, Rivera-Monroy VH, Salgado J, Sannel ABK, Seifollahi-Aghmiuni S, Sjöberg Y, Terskii P, Vigouroux G, Licero-Villanueva L, Zamora D. Data for wetlandscapes and their changes around the world. Earth Syst Sci Data. 2020;12:1083-100. https://doi.org/10.5194/ essd-12-1083-2020.

16. Thorslund J, Jarsjo J, Jaramillo F, Jawitz JW, Manzoni S, Basu NB, Chalov SR, Cohen MJ, Creed IF, Goldenberg R, Hylin A, Kalantari Z, Koussis AD, Lyon SW, Mazi K, Mard J, Persson K, Pietro J, Prieto C, Quin A, van Meter K, Destouni G. Wetlands as large-scale nature-based solutions: status and challenges for research, engineering and management. EcolEng. 2017;108:489-97. https://doi.org/10.1016/j.ecoleng.2017.07.012.

17. McCauley LA, Anteau MJ, van der Burg MP, Wiltermuth MT. Land use and wetland drainage affect water levels and dynamics of remaining wetlands. Ecosphere. 2015. https://doi.org/10.1890/ES14-00494.1.

18. Mitsch WJ, Gosselink JG. The value of wetlands: importance of scale and landscape setting. Ecol Econ. 2000;35:25-33. https://doi.org/10.1016/ S0921-8009(00)00165-8.

19. SGU. Geologins betydelse vid våtmarksåtgärder - Sätt att stärka tillgången på grundvatten (The role of geology in wetland creation and restoration -ways to reinforce access to groundwater; in Swedish). 2019. SGU Rapport 2019:15.

20. Collaboration for Environmental Evidence. Guidelines and Standards for Evidence synthesis in Environmental Management. Version 5.0 (Pullin AS, Frampton GK, Livoreil B, Petrokofsky G, Eds). 2018. www.environmentalev idence.org/information-for-authors. Accessed 10 July 2020.
21. Haddaway NR, Macura B, Whaley P, Pullin AS. 2020. ROSES for systematic review protocols. Version 1.0; doi: 10.6084/m9.figshare.5897269.v4. Accessed 28 Aug 2020.

22. Bussell J, Jones DL, Healey JR, Pullin A. How do draining and re-wetting affect carbon stores and greenhouse gas fluxes in peat soils. CEE review 08-012 (SR49). Collaboration for Environmental Evidence. 2010.

23. Haddaway NR, Burden A, Evans CD, Healey JR, Jones DL, Dalrymple SE, Pullin AS. Evaluating effects of land management on greenhouse gas fluxes and carbon balances in boreo-temperate lowland peatland systems. Environ Evid. 2014;3:5.

24. Land M, Granéli W, Grimvall A, Hoffmann CC, Mitsch WJ, Tonderski KS, Verhoeven JTA. How effective are created or restored freshwater wetlands for nitrogen and phosphorus removal? A systematic review. Environ Evid. 2016. https://doi.org/10.1186/s13750-016-0060.

25. Swedish Hydrological Council. Hydrologisk ordlista (Glossary of hydrology). 2020. https://hydrologi.org/hyd_lex/. Accessed 6 July 2020.

26. Harzing A-W. Publish or Perish software. 2007. https://harzing.com/resou rces/publish-or-perish. Accessed 14 Apr 2020.

27. Fetter CW. Applied Hydrogeology. 4th ed. London: Pearson; 2014.

28. Ehlers J, Gibbard PL, Hughes PD, 2011. Quaternary glaciations-extent and chronology. Elsevier. https://booksite.elsevier.com/9780444534477/ index.php

29. Beck HE, Zimmermann NE, McVicar TR, Vergopolan N, Berg A, Wood EF. Present and future Köppen-Geiger climate classification maps at 1-km resolution. Sci Data. 2018;5:180214. https://doi.org/10.1038/sdata .2018 .214 .

\section{Publisher's Note}

Springer Nature remains neutral with regard to jurisdictional claims in published maps and institutional affiliations.
Ready to submit your research? Choose BMC and benefit from:

- fast, convenient online submission

- thorough peer review by experienced researchers in your field

- rapid publication on acceptance

- support for research data, including large and complex data types

- gold Open Access which fosters wider collaboration and increased citations

- maximum visibility for your research: over $100 \mathrm{M}$ website views per year

At BMC, research is always in progress.

Learn more biomedcentral.com/submissions 